\title{
Tax Incentive Programs and Unemployment Rate
}

\section{Kala Seetharam Sridhar*}

\begin{abstract}
This paper answers the question: What are the effects of tax incentive programs on an area's unemployment rate? A model is developed that describes the determination of unemployment in an enterprise zone. The estimation of unemployment rate using Census data for Ohio, taking into account the treatment effects problem, shows that such programs have a significant impact in reducing unemployment. The net impact of being an enterprise zone for a duration of one year is approximately a 3 percentage point reduction in area unemployment. The results also suggest that three to five years could be the optimum period for offering incentives.
\end{abstract}

\section{INTRODUCTION}

\section{Importance of Problem and Motivation for Research}

Many regional development policies that attempt to increase employment do so by providing incentives to firms. Such policies include industrial revenue bonds, property tax abatements, direct state loans, and customized industrial training. Until recently, such policies were considered ineffective because they were believed to redistribute existing employment between areas, leaving total employment unchanged. Thus, it was argued that such policies are often zerosum or negative-sum in their effects (see Netzer 1991; Rubin and Zorn 1985). For this and other reasons, these policies were said to be detrimental to the long-run growth of the areas that adopted them.

There have been debates regarding the nature of regional development policies in policy circles too. One policy tool that has been frequently used is the enterprise zone (EZ). EZs are geographically targeted areas chosen for development and are designated on the basis of certain distress criteria. Firms that locate in the area and create jobs are given tax credits, abatements, and exemptions. The underlying assumption is that firms and employees in the zone area benefit because of a reduction in the price of capital and/or labor, and there is expanded investment and employment generation through deregulation.

Controversy exists as to whether or not EZ tax abatements are beneficial to areas that adopt them. Concern about the benefits of competition between locations has been at the forefront of policy debates in the states. In Ohio, this debate has been quite extensive because of the existence of a large number (about 330) of

\footnotetext{
*Assistant Professor, Indian Institute of Management, Prabandh Nagar, Lucknow, India. The work for this paper is supported by a grant from the U.S. Department of Housing and Urban Development. However, the interpretations and findings in the paper are not views of the U.S. government. I am very thankful to my adviser, Professor Charles Adams, and my dissertation committee, consisting of Don Haurin, Mary Marvel, and Anand Desai, for their extremely helpful comments. All errors remain mine.
} 
EZs relative to other states. ${ }^{1}$ Most parts of Ohio are designated as EZs or as areas providing tax incentives under other programs. Recent legislative discussions surrounding the EZ program in Ohio centered around the "pirating" of firms in one area by neighboring areas (see Hill 1994) that offered tax incentives. Whether these incentive programs and the resulting tax competition are conducive to development remains a debate in both the literature and policy circles (Byrnes and Sridhar 1996). This policy debate is the policy version of the "zero-sum" game argument in the literature.

One of the objectives of the EZ program in Ohio is to reduce unemployment. The purpose of this paper is to examine Ohio's EZ program and other tax incentive programs to see if they are beneficial in reducing unemployment of the areas that have adopted them. This is an important question because the literature and policy circles are ambiguous about the effect of these programs. In the paper, I develop a model that shows how tax incentive programs affect unemployment of the areas that adopt them. The model shows that tax incentive programs can be expected to reduce an area's unemployment rate by increasing labor productivity. I test the model empirically using data from Ohio's incentive programs and examine whether tax incentives are responsible for lowering unemployment in Ohio's census block groups. I find that tax incentive programs have a statistically significant impact in reducing unemployment in the areas that adopt them, indicating that such programs may not be totally detrimental to the development of those areas.

\section{Overview of Paper}

In the next section I summarize the regional economic development literature evaluating EZs and tax incentive programs in the various states. Next, I describe the analytical model that forms the basis for the empirical work. I then explain the data and research methodology used for the estimation. The subsequent sections focus on the results. In these sections, I report the results from the estimation of unemployment rate taking into account the treatment effects problem. The final section evaluates the policy implications arising from the estimation.

\footnotetext{
1Ohio's program contrasts sharply with New Jersey's Urban Enterprise Zone program, which allows limited designation. So far there are only 10 zones in New Jersey (see Boarnet and Bogart 1996). However, in Ohio, all areas that meet at least one of six distress criteria or that meet minimum population requirements can potentially apply and applicants cannot be rejected zone designation on the basis of arbitrary criteria. According to the Ohio Department of Development, only three counties (Columbiana, Geauga, and Holmes) have not applied for zone designation even though they are potentially eligible, based on their distress criteria. Two of these counties have documented use of the community reinvestment area program, under which part or all of these counties can offer tax incentives to firms, leaving one county that does not provide tax incentives to firms.
} 


\section{LITERATURE REVIEW}

There is a vast body of policy and empirical literature that evaluates EZs and other tax incentive programs. ${ }^{2}$ Some of this literature (Seyfried 1990; Papke 1994; Ge 1995) has examined whether supply-side incentives affect unemployment in the areas that adopt them. The labor literature has studied the impact on the unemployment rate of various demographic characteristics and industrial composition, but has done little to examine the effect of government policies on the unemployment rate (Ehrenberg and Smith 1994 acknowledge the effect of such programs on the unemployment rate).

Since the studies use different techniques and measures of evaluation, it is difficult to compare the findings across the board. In any case, the findings that emerge with regard to the effectiveness of tax incentive programs are mixed. In general, earlier studies (studies in the period immediately following the introduction of EZs in the United States) find EZs to be favorable. A study of ten EZs (in various states) by the U.S. Department of Housing and Urban Development (1986) finds these zones to be valuable tools for marketing these distressed areas. The study by Erickson and Friedman (1989) also belongs to this category of studies, showing that EZs created employment, with more than half of the jobs being held by zone or low-income residents. Using unemployment claim data, Papke (1994) finds a significant reduction in unemployment claims under Indiana's EZ program (as much as 19 percent). ${ }^{3}$ Ge's (1995) theoretical model shows that the presence of an EZ lowers the unemployment rate of the area, but no empirical evidence is presented.

The other side of the evidence from the literature has been that EZs are used as a tool to divert employment away from one area to another and that they are not effective in achieving the objectives for which they are created. A study by the U.S. General Accounting Office (1988) of EZs in Maryland is quite pessimistic with regard to the effectiveness of EZs. Based on interviews of EZ officials and time series analysis of employment data, it concludes that the EZ was not responsible for any of the employment created in the three zones (Hagerstown, Salisbury, and Cumberland) that it examines. Seyfried's (1990) empirical work shows that the property tax rate (which is used as a measure of the EZ in his regression) does not have a substantial impact on unemployment. However, this result is quite restricted because only one measure of the EZ's existence, i.e., the property tax rate, is used. A complete description of state EZ programs shows that EZs have general features apart from property tax rates (deregulation and right-to-work

${ }^{2}$ These studies have evaluated EZs in various states-Indiana, Illinois, Ohio, Kentucky, New Jersey, and California (Rubin and Armstrong 1989; Erickson and Friedman 1989; Seyfried 1990; Boarnet and Bogart 1996). Ge (1995) and Seyfried (1990) develop analytical models to analyze the impact of EZs. Some studies focus on case studies of specific EZs (U.S. Department of Housing and Urban Development 1986; U.S. General Accounting Office 1988; Rubin and Wilder 1989; Dabney 1991; Staley 1991; Coopers and Lybrand 1993; Theirl 1994). Wilder (1996) provides a near-comprehensive review of the literature on EZs. Related regional economic development literature evaluates incentives provided to particular firms (Marvel and Shkurti 1993). Other literature in the area has focused on policy recommendations that follow from experience with regional economic development policy in the United States (Levitan and Miller 1992; Courant 1994; Bartik 1995; Eisinger 1995; LeRoy 1994).

${ }^{3}$ The limitations of data on unemployment claims as compared to data on actual employment status are described in the section on data. 
laws are examples) that distinguish them from other programs. So, a more general proxy for tax incentive programs (as used here) is preferable to using just one measure of the program.

Another problem with the literature is that it does not explain the cause of unemployment in the EZ. Butler (1981), one of the pioneers of the EZ concept in the United States, argues that minimum wage legislation is the primary cause of unemployment in the United States and so relaxing this minimum wage constraint in the areas designated as EZs would alleviate their unemployment. But minimum wages do not explain why unemployment tends to get concentrated in certain areas (that get designated as EZs). This work attempts to address this gap in the literature. It explores the cause of unemployment in the EZ and the effects of tax incentive programs, which forms the basis of the estimation.

\section{MODEL}

\section{A Model of Unemployment}

The model of unemployment that is developed here is based on the neoclassical assumption of high reservation wages. This means that individuals in the EZ are unemployed because they have high reservation wages relative to the market wage prevailing in the EZ. The assumption of high reservation wages is valid because of the existence of various safety net programs, such as unemployment insurance and social security benefits, in the United States. Generous unemployment benefits cause an individual's reservation wage to be high by reducing his or her costs of remaining unemployed. In fact, Feldstein (1978) argues that a combination of a high marginal tax on earnings and no tax on unemployment compensation makes the private cost of unemployment small and causes an individual to remain unemployed by increasing his or her reservation wage.

The market wage in the EZ area is low because profit-maximizing employers are willing to pay a wage that only matches the skill of the workers. It is reasonable to imagine that the marginal product of labor in the EZ is less than in the non-EZ area. The literature on EZs points to the blight in these areas (Ge 1995; Erickson and Friedman 1989; Levitan and Miller 1992; Wilder 1996), which, according to this model, is due to the initially low capital-labor ratio in the EZ. The low capital-labor ratio results in low productivity and wages for those who are employed as well as those who are unemployed.

The labor in the EZ area is also immobile because of psychological ties to the area and costs of relocation. The migration literature has shown that those with poor skills and little education are the most likely to be immobile. The most basic data on geographical mobility that control for age group are available from the Current Population Reports from 1987-90. These data show that interstate migration rates for people in the age group 30-34 is 3.4 percent for those with 9-11 years of education and 8.7 percent for those with over 17 years of education (Ehrenberg and Smith 1994; also see Schwartz 1973). Thus, the low skills of the unemployed in the EZ coupled with insufficient information regarding job opportunities out- 
side their state (or even local area for that matter) ${ }^{4}$ make them continue to stay where they are.

Formally, the unemployment status $\left(\mathrm{US}_{\mathrm{ij}}\right)$ of individual $\mathrm{i}$ living in the $\mathrm{jth}$ area is determined by the difference between reservation and market wage: 5

$$
\mathrm{US}_{\mathrm{ij}}=\mathrm{f}\left(\mathrm{w}_{\mathrm{ij}}^{\mathrm{r}}-\mathrm{w}_{\mathrm{ij}}\right) \text {, }
$$

where $\mathbf{w}_{\mathrm{ij}}^{\mathrm{r}}$ is the reservation wage and $\mathrm{w}_{\mathrm{ij}}$ is the market wage of the ith individual living in the jth area. The unemployment rate of the jth area may be obtained by summing over the unemployment status of $i$ individuals living in the area. It may be written as:

$$
\mathrm{U}_{\mathrm{j}}=\sum_{\mathrm{i}} \mathrm{US}_{\mathrm{ij}} / \text { Population. }
$$

Substituting for unemployment status,

$$
\mathrm{U}_{\mathrm{j}}=\sum_{\mathrm{i}} \mathrm{f}\left(\mathrm{w}_{\mathrm{ij}}^{\mathrm{r}}-\mathrm{w}_{\mathrm{ij}}\right) \text { /Population. }
$$

As Equation 3 shows, the unemployment rate in the jth area is dependent on the extent to which reservation wages of individuals are higher than market wages in the area. ${ }^{6}$ The unemployment rate of the EZ is high since, for a substantial portion of the labor force, reservation wages are high relative to market wages in the area.

Prior to the designation of an area as an EZ, profit-maximizing employers have little incentive to hire workers with low skills. Under these circumstances, EZ designation of the area acts as an important place-oriented policy to improve the blighted area through tax abatements. Tax abatements provide firms with 4Labor markets for college-educated workers are more likely to be regional or national than are labor markets
for those with less education. In addition, even if job opportunities exist beyond the local area, insufficient infor-
mation prevents those with less education (and skills) from having access to those jobs. For instance, for a jani-
tor in Beaumont, Texas, finding out about employment opportunities in the north central region is like looking
for the proverbial needle in a haystack (see Ehrenberg and Smith 1994).
5Some labor literature has modeled the unemployment status of an individual in a similar manner (see Barron
and Mellow 1981; Holzer 1986). Barron and Mellow (1981) estimate a reduced form model while attempting to
answer the question of what factors affect the subsequent labor force status of an unemployed individual. Their
data are from the May 1976 and June 1976 Current Population Survey and from a special supplemental survey of
unemployed respondents in May 1976 regarding current job-seeking activities for a sample of 1,307 individuals.
They measure the reservation wages with the response to the question: “What is the lowest wage or salary you
would accept...for this type of work?" They estimate the probability of an unemployed individual becoming
employed in a given period as a function of the relative reservation wage (ratio of reservation wage to average
wage in the area labor market), along with other factors. They find that a higher relative reservation wage
reduced employment probability, similar to the expectation in this model.

In an attempt to explain the "shockingly high rates of unemployment which plague black youth," Holzer (1986) estimates the wage and the duration of unemployment as a function of reservation wage and other factors. Holzer (1986) uses data from the youth cohort of the National Longitudinal Survey (NLS) in 1979 and 1980. The sample is limited to white and black males, aged 16-21 in 1979, who are nonstudents. The reservation wage is measured in the NLS as the response to the question: "What would the wage or salary have to be for you to be willing to take it?" Holzer finds that young blacks seek wages that are comparable to those of young whites in absolute terms, but which are higher relative to what is received by them. He finds that the relatively higher reservation wages of young blacks contribute to their unemployment durations and somewhat to their lower, subsequently received wages. He concludes that changes in reservation wages might help to explain the trends in the wages and employment of young blacks in recent years.

Thus, the finding from the labor literature is that higher reservation wages relative to market wages lower employment probability for individuals and contribute to their unemployment status, consistent with the model here.

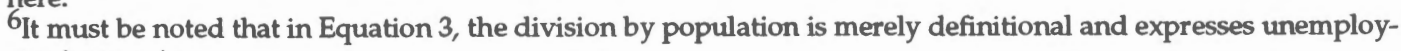
ment as a rate. 
incentives for investment, thus increasing the capital-labor ratio, the productivity of workers, and ultimately the market wage offered to them. At the point when the market wage exceeds the reservation wage in the EZ, unemployed individuals in the area become willing to work, employment increases, and the unemployment rate falls. The tax abatement on capital also leads to in-migration of capital into the EZ and, depending on the elasticity of substitution between capital and labor, results in increases in the employment of labor. With increasing employment, the unemployment rate in the EZ decreases to a level below its initial rate at the optimum. At this optimum, unemployment in the non-EZ areas remains unchanged. This occurs because, as Tobin (1972) demonstrates, an economy operating at a natural rate of unemployment of 5 to 6 percent still has (more than 20 percent) excess capacity in its capital stock. Thus, the EZ acts only as a tool to direct the excess capital away from the full-employment areas to high unemployment areas. ${ }^{7}$ The model developed here shows how tax incentives, along with wages and reservation wages, affect the unemployment rate of the area adopting them.

\section{Implementation of the Model}

When this model is estimated, there are no collinearity or confounding problems between tax incentives and wages, both of which affect unemployment rate in the model. This is because the model is estimated in reduced form. The estimation of unemployment rate in reduced form is consistent with the literature (see Pantuosco and Parker 1998), which shows that sociodemographic characteristics, such as age, race, sex, and education, determine the unemployment rate. Here, these sociodemographic characteristics are used, instead of wages and reservation wages, as exogenous variables. As should be obvious, there are no collinearity or confounding problems between sociodemographic characteristics (which determine wages) and tax incentives. Figure 1 illustrates diagrammatically the determination of the unemployment rate. It shows the reduced form of the model in which it is estimable.

The expectation from the theoretical model is that areas with tax incentive programs see a reduction in their unemployment rate. ${ }^{8}$ Thus, in the estimation, if the coefficient on tax incentives is found to be negative and statistically significant, it may be inferred that tax incentive programs decrease the area's unemployment, consistent with the theoretical model.

In addition to the effect of the tax incentive program on unemployment rate, I control for the time period (duration) for which the program has been in

\footnotetext{
${ }^{7}$ The assumption of this model is that nonzone areas are low-unemployment areas. Empirically, too, it is easy to imagine that non-EZ areas have a natural rate of unemployment (which is close to full employment). This assumption is consistent with EZ programs in most of the states, which require high unemployment as a criterion for zone designation. However, in Ohio, low-unemployment areas may be designated as zones. (See the end of this section for criteria for zone designation in Ohio.)

8 It must be noted that tax incentive programs and the unemployment rate are determined simultaneously because a high unemployment rate is a criterion for zone designation in Ohio (see the end of this section for the description of criteria for zone designation). I explain the procedure to alleviate the endogeneity between zone designation and unemployment in the section on methodology.
} 
existence in the area..$^{9}$ One can imagine that the tax incentive program reduces the unemployment rate of an area, but there could be some optimum period for which it is desirable. This effect makes it necessary to control for duration of the program by including it as another variable.

\section{FIGURE 1}

Determination of Unemployment Rate

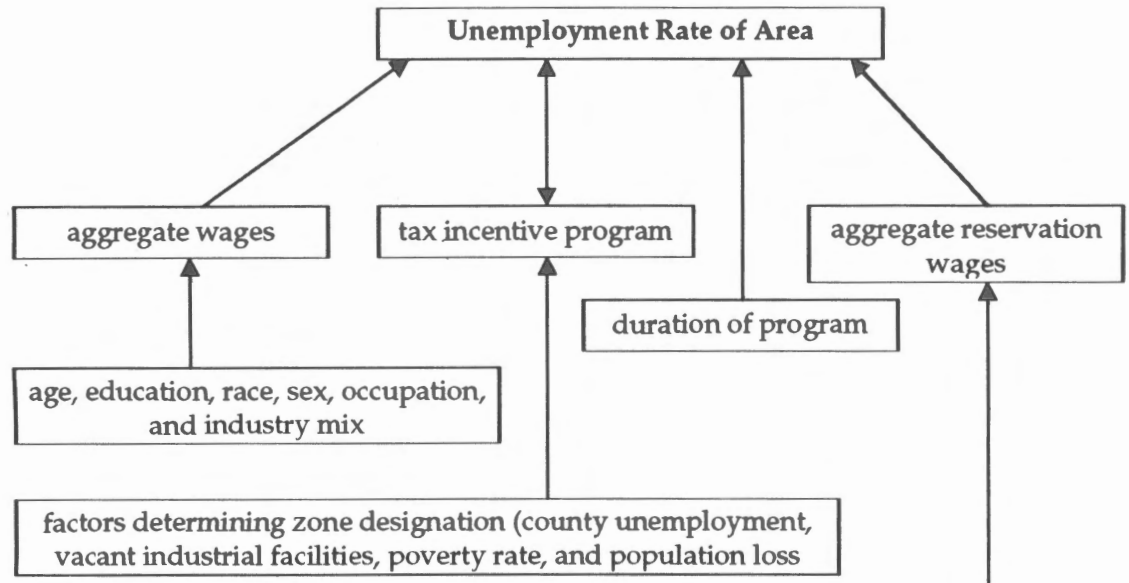

exogenous factors (age, education, race, and gender composition)

I have taken the duration of the program as exogenously determined in the model. My discussions with the Ohio Department of Development (which administers the EZ program in the state) indicate that the timing of zone designation ${ }^{10}$ chosen by areas is a nonrandom process. Specifically, the duration of tax incentive programs depends on factors, such as pro-growth coalitions, political support, and bureaucratic and institutional structures needed to implement the incentives in the communities, that are not measurable (no data are available on these

${ }^{9}$ I looked at the literature to see not only how a treatment effect (which here is the tax incentive program), but also the duration (how long the treatment has been in effect) of the treatment impacts the outcome variable of interest (unemployment rate here). I found the following from a literature search on treatment effects models with regard to how the duration of the treatment has been handled:

a. Ashenfelter (1977) looks at the effect of the treatment by including explicit year dummies for several years previous to the period in which the treatment actually came into effect. Although this is one way of handling duration, the result shows a before-and-after effect of the treatment (which in this case was the effect of a postschooling training program on participants' earnings).

b. Ham and LaLonde (1996) estimate an employment rate hazard model for participants in an employment training program. In the hazard model estimation, the duration of employment and unemployment spells and their squares are used as independent variables along with other control variables.

c. Korenman and Neumark (1991) employ the treatment effect dummy (marital status of individuals) as well as the duration of the effect (number of years of marriage) on earnings.

Thus, there appears to be some literature that treats the duration of the treatment as an independent variable. Others apparently treat this kind of model as a hazard model for which, however, a major extension of this research is needed.

10 The duration for which an area is an EZ can vary when it either gets designated or expires early. In my sample and empirical work, the problem of determining what factors determine the duration of zone designation is purely a function of what determines early and late zone designation (without worrying about when they expire) since in my sample expired zones are excluded. See Footnote 20 for an explanation of why this was done. 
characteristics at the zone level). These factors do not appear in the theoretical model and so duration is considered exogenous.

There is another reason why duration in the current sample is random empirically with respect to the unemployment rate. If the duration variable had systematically varied across zones and nonzones, taking zero values only for lowunemployment areas, there could have been a bias in the estimates. But in the sample, this problem does not arise because there are a large number of nonzone Census block groups with higher unemployment rates (than zones) for which the duration variable takes a zero value.11

The expected impact on the unemployment rate of the duration of the tax incentive program is ambiguous. This is because the time element introduces some amount of dynamism in the static model. One may surmise that the unemployment rate might vary in a nonlinear fashion with respect to duration, at first increasing, then decreasing, or decreasing at first and then increasing. But in the context of this static model, distinctions between short-run versus long-run responses cannot be made. In order to track this ambiguity, the squared term of duration has been included as an independent variable, along with duration. If the duration of the program had a positive impact and its square had a negative impact on the unemployment rate, then it might be inferred that the tax incentive program initially increases but eventually decreases the unemployment rate of the area.

The impact of the tax incentive program can be determined along with the duration variables. If the tax incentive dummy were found to be significantly affecting the unemployment rate, the duration variable would enable us to understand the time period over which the impact of the tax incentive program can be expected to be valid. ${ }^{12}$

In the estimation, I also control for the occupational composition of the area because different occupations, as reflected in the proportion of employment in technical or routine administrative occupations as opposed to employment in service occupations, have different unemployment rates due to different demand conditions. For instance, those employed in routine administrative and technical occupations might be less likely to lose their jobs at any given point in the business cycle than those in service occupations, such as private household occupations, for which demand is likely to be elastic. Therefore, I expect the proportion employed in routine administrative and technical occupations to have a negative impact on the area's unemployment rate and the proportion of employment in service occupations to have a positive impact on the area's unemployment rate.

In addition, I include measures that reflect the area's economic base, such as the proportion of total employment in manufacturing as compared to employment in services, to test for their effect on the unemployment rate. These measures reflect the importance of these sectors in the area's economic base, and it is neces-

\footnotetext{
11 See the section on variable definitions for how the duration variable is defined for zones and nonzones.

12 In the results section, I demonstrate how to calculate the impact of the tax incentive program on the unemployment rate using estimates on the tax incentive dummy and the duration variables.
} 
sary to control for them. I expect the proportion of manufacturing employment in the area to have a positive impact on the unemployment rate and the proportion in service employment to have a negative impact on the unemployment rate. This is because of the decreasing importance of manufacturing and increasing importance of services in the economic base of most local economies.

Demographic characteristics such as race, age, sex, and education also influence an area's unemployment and are included in the model to be estimated. I expect areas with larger proportions of African Americans to have higher unemployment (positive effect). ${ }^{13}$ This is because, as a group, African Americans generally have lower levels of education and poorer skills. For similar reasons, areas with a higher proportion of women are likely to have higher unemployment. The expected sign, then, on the proportion of males is negative. Areas with better average education are expected to have lower unemployment. This is because education implies the presence of certain skills. If job opportunities that require those skills do not exist in the area, individuals are likely to move out of the area. This reduces the labor force and in turn lowers the unemployment rate of the area. This is consistent with the theoretical model that points to the immobility of lesseducated individuals in the EZ area and their consequent unemployment. Thus, the unemployment rate of better-educated areas is likely to be lower (due to higher mobility of the better-educated labor force). The sign on the variable representing the proportion with bachelor's degrees is therefore expected to be negative. Finally, older persons are likely to have greater work experience and thus be employed. So, areas with a higher average age are likely to have a lower unemployment rate. The expected sign on the age variable, therefore, is negative.

The unemployment rate is estimated as a function of these variables. The basic model of unemployment in the ith census block group may be summarized as follows:

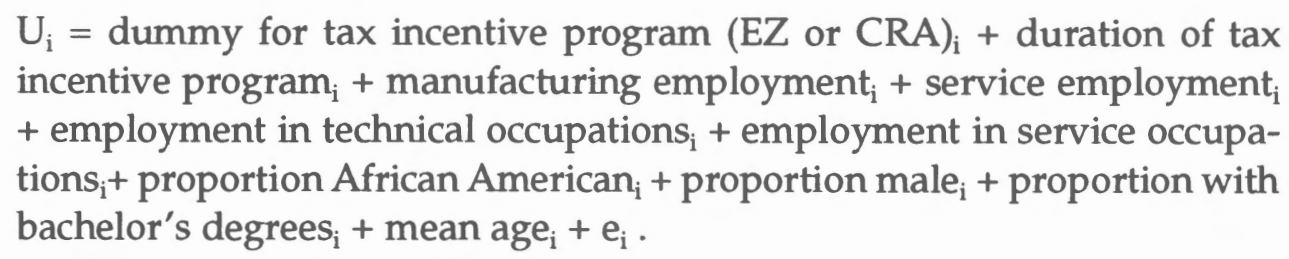

It may be noted that in Figure 1 and Equation 4, tax incentive programs and the unemployment rate are determined simultaneously. This is because a high unemployment rate is a criterion for zone designation in Ohio.

In Ohio's EZ program there are two types of zones that are allowed: fullauthority zones and limited-authority zones. Full-authority zones are distress based. They have to satisfy at least one of the following six distress criteria:

1) Unemployment of 125 percent of the state average unemployment during the most recent 12 months;

2) At least 10 percent population loss between 1980 and 1990;

${ }_{13}$ Precise definitions of the variables are given in the section on empirical work. 
3) Prevalence (minimum of 5 percent) of vacant or demolished commercial or industrial facilities;

4) Fifty-one percent of the population below 80 percent of the area's median income;

5) Specific vacant industrial facilities (zone incentives apply only to those facilities); and

6) Income-weighted tax capacity of the school district below 70 percent of the state average.

On the other hand, it is sufficient for limited-authority zones to demonstrate minimum population requirements to be designated as zones. This requirement is that EZs proposed within counties of a population greater than 300,000 must have a minimum population of 4,000 . EZs proposed within counties of a population less than 300,000 must have a minimum population of 1,000 . Both full-authority zones and limited-authority zones can offer tax incentives to firms that locate there.

Due to criterion (1), above, causality can be reversed in a regression of unemployment as a function of tax incentive programs. I explain the procedure to alleviate this endogeneity in the section on methodology.

\section{DATA}

Unemployment rates do not exist by EZ or tax incentive area level in Ohio, but self-reports of personal employment at the block group level are available for 1990 from the (Ohio) Census summary tape files (STF3A). The self-reported data on employment status in the Census are based on responses to questions asking for detailed information regarding persons' activities in a reference week. In the Census, all civilians age 16 years and over who:

1) are "at work" as paid employees, work in their own business or profession, or farm; or

2) are "with a job, but not at work" during the reference week due to illnesses, bad weather, industrial dispute, vacation, or other personal reasons

are classified as employed. Those who are not in the categories "at work" or "with a job, but not at work" during the reference week and who:

1) are looking for work during the last four weeks; and

2) are available to accept a job

are classified as unemployed, in addition to those waiting to be called back to a job from which they had been laid off.

The superiority of data on self-reported employment when compared to data on unemployment claims (which Papke 1994 uses in her evaluation of Indiana's EZ program) is clear. First, self-reported employment data cover all civilians 
age 16 years and over. Although the Census data are based on a sample, appropriate weighting is done to ensure representativeness of the sample. ${ }^{14}$ However, data on unemployment compensation claims exclude persons who have exhausted their benefit rights, new workers who have not earned rights to unemployment insurance, and persons losing jobs not covered by unemployment insurance systems (including some workers in agriculture, domestic services, and religious organizations, and self-employed and unpaid family workers). Second, the number of employed persons "at work" could be understated in self-reported data because persons who have irregular, casual, or unstructured jobs sometimes report themselves as not working. However, this problem is alleviated since other persons on vacation or sick leave erroneously report themselves as being "at work," overstating the number in the category. Thus, the combined impact of these errors in self-reporting on total employment (or unemployment) is nullified.

A disadvantage of self-reported data from the Census is that it depends on the reference week, which is not the same for all respondents since the enumeration is not completed in a week. Since persons can change their employment status from one week to another, the lack of a uniform reference week may mean that the employment data do not reflect the reality of the employment situation of any given week. Since I am not looking at unemployment during any period in a year, the reference week is not a limitation.

Based on this self-reported data, I am able to compute unemployment rates for Ohio's Census block groups. Census data is also the only way in which I am able to determine whether a tax incentive program is in place. I do this by overlaying a map of Ohio's EZs on a map of its Census block groups. ${ }^{15}$ I find that out of Ohio's 11,621 Census block groups, about 8,300 block groups have EZs. An additional 1,000 block groups have tax incentive programs called community reinvestment areas (CRAs). ${ }^{16}$ Thus, a total of 9,300 block groups are tax incentive areas and the remaining 2,321 block groups are non-tax incentive areas.

\footnotetext{
14The estimates in the Census data for each person or housing unit are obtained from an iterative ratio estimation procedure resulting in the assignment of a weight to each sample person or housing unit. The procedure used by the Census Bureau to assign weights is performed in geographically defined "weighting areas" having a minimum sample of 400 persons. Within a weighting area, the procedure is applied to these groups: 17 household-type groups; groups with a sampling rate of one in two; groups with sampling rate less than one in two; householders/nonhouseholders; and 180 aggregate age-sex race-Hispanic origin categories. The weighting is done in four stages as follows:

a. The first step is to assign an initial weight to each sample person record. This weight is approximately equal to the inverse of the probability of selecting a person for the Census sample.

b. In stage II, the stage I adjusted weights are again adjusted by the ratio of the complete Census count to the sum of the stage I weights for sample persons in each stage II group (groups with deferent sampling rates).

c. In stage III, the stage II weights are adjusted by the ratio of the complete Census count to the sum of stage II weights for sample persons in stage III group (householder/nonhouseholder).

d. In stage IV, the stage III weights are adjusted by the ratio of the complete Census count to the sum of stage III weights for sample persons in each stage IV group (age/sex race/Hispanic origin).

The weighting procedure for housing units is essentially the same as that for persons, except that vacant units are treated differently. The procedure for occupied housing units is done in four stages (same as for persons), but the procedure for vacant units is done in a single stage (with three categories: vacant for rent, vacant for sale, and other vacant). This weighting ensures representatives of the sample used in the Census.

15 The digital map of Ohio's EZs is obtained from the Ohio Department of Development. The digital map of Ohio's Census block groups is obtained from the Center for Mapping at the Ohio State University. The overlaying of the two maps is done using the Geographic Information Systems (GIS) software ARCVIEW.

16 The CRA program provides tax incentives for property improvements that could result in job creation.
} 
The availability of data on other demographic characteristics of Census block groups (STF3A files) makes it possible to estimate these characteristics for the Census block groups of the state. Relevant characteristics, in addition to selfreported employment, on which data are available for persons at the Census block group level, are age, whether African American, whether male or female, and educational attainment.

\section{EMPIRICAL WORK: RESEARCH METHODOLOGY}

The estimation of the unemployment rate is performed taking into account the treatment effects problem caused by the endogeneity of tax incentives. Out of the 322 EZs in Ohio, the majority ( 278 zones) are designated on the basis of population (limited-authority zones), and the rest (44) are distress based (satisfying at least one of the six criteria). The Ohio Department of Development does not have data on how many of the 44 distress-based zones have high unemployment (125 percent of the state's average for the last 12 months). But if a high correlation is assumed between the various characteristics of distress, it may be reasonably said that 44 zones are high-unemployment areas.

\section{Treatment Effects Problem}

The treatment effects (endogeneity) problem is alleviated by adopting the instrumental variable approach. Exogenous characteristics that determine zone designation (median income, prevalence of vacant commercial or industrial property, population loss, unemployment, and taxable capacity) are used as instruments in a two-stage least squares estimation of the unemployment rate (Equation 4).

The area's poverty rate is used as a measure of the income criterion (51 percent of the population is below 80 percent of the area's median income) required for zone designation, and is used as an instrument. A second instrument is the proportion of vacant housing units in an area. This is used as a measure of the prevalence of vacant or demolished commercial or industrial facilities in the area, which is required for zone designation. Data on housing units are used because only data on residential structures are reported in the Census. I acknowledge that there could be a divergence between the prevalence of vacant commercial and/or industrial facilities and that of vacant housing units. In areas zoned for industrial use, where some units are vacant, for instance, there are no housing units at all. For these areas, this measure would indicate zero vacant housing units, meaning that the area does not need zone designation. This conclusion based on housing units is, however, not reflective of the true situation. At the other extreme, in areas zoned for residential use, if a large number of vacant housing units exist, then this measure would indicate that the area needs rehabilitation or could be used for other purposes, thus deserving tax incentives. In this situation, the result based on the prevalence of vacant housing units would be correct because in block groups that contain a combination of housing and commercial facilities, I expect the prevalence of vacant housing units to be a fairly good mea- 
sure of the existence of vacant industrial or commercial facilities in the area. Thus, the chosen measure is a good proxy for its intended purpose.

The unemployment rate for the county (in which the Census block group is located) at the time of zone designation (1982) is used as another instrument. The county's unemployment rate undoubtedly influences zone designation, making it desirable as an instrument.

Finally, I use two measures of net migration into the area17-one at the Census tract level and the other at the county level-as instruments that determine zone designation. These are used as measures of the population loss criterion for zone designation. It may be expected that areas that experience little inmigration are also the ones with population loss. The tract-level measure is a dummy because the areas of Census tracts changed over 1980-90 making direct computation of net change in population at the tract level impossible. At the county level, it is possible to compute the magnitude of the population change and so I use the net change in population over 1980-90 as an instrument.

Since there are no data on taxable capacity at the Census block group or tract level, I am unable to use measures of this variable as an instrument. However, it is easy to imagine that there is a high correlation between the poverty rate of an area and its taxable capacity. Areas that have larger proportions of their populations below the poverty level are frequently the ones whose school districts have their income-weighted tax capacity below the state average. Therefore, the poverty rate, which is used as an instrument in the estimation, is a good measure of the income-weighted tax capacity criterion also.

\section{Variable Definitions}

1) The block group's unemployment rate (the dependent variable) is computed according to the method recommended by the Ohio Department of Development. According to this procedure, I first estimate the unemployment rate for all the counties based on the ratio of unemployed to total labor force aggregated in the 1990 Census at the county level. I then estimate a similar ratio for the block groups, obtaining a raw unemployment rate for every block group. I take the ratio of block group to county unemployment rates computed in this way. This ratio multiplied by the published county unemployment rates (published by the Ohio Bureau of Employment Services) gives me the block group unemployment rate that is used in the estimation.

2) The tax incentive program dummy $=1$ if a tax incentive program (EZ or CRA) is in place, 0 if not. The definition of the EZ dummy is easily achieved by overlaying the map of EZs over that of the block groups. The dummy for the CRA program is more difficult to arrive at. I find out whether CRA and EZ areas

${ }^{17} \mathrm{~A}$ gross measure of in-migration to an area would be the percentage in-migration of households over 1985-90 into the area since it is plausible for in-migration to have occurred during this period, after the EZ program came into being in the state in 1982. However, what are used as measures of in-migration to the area in the estimation are net measures that take into account population loss in the area. 
overlap by talking to the 282 CRAs in Ohio (all certified in the pre-1994 period). ${ }^{18}$ When my discussions with the communities indicate that, in areas that have both a CRA and an EZ, the CRA is outside the enterprise zone, I identify the Census tract numbers for these cities from the Census STF3A files and include them as areas having tax incentive programs. Thus, areas that have nonoverlapping CRAs and EZs and those that do not have an EZ, but use the CRA for purposes of job creation (provide CRA abatements to industries), are identified as having a tax incentive program. ${ }^{19}$ The non-tax incentive areas (with 0 for the dummy) in the estimation are those areas in which no tax incentives are provided to commercial/industrial property that resulted in job creation. However, it is possible for abated residential property to exist in non-tax incentive areas, according to the way in which the variable is defined here. Although abatements to residential property could result in job creation (as with the CRA program), I do not account for these incentives. The tax abatements granted in a majority of the CRAs in Ohio are for commercial and industrial uses (based on my discussion with the CRA administrators). So, not accounting for residential incentives of the CRA program should not affect the results to a great extent.

3) The duration for which the EZ has been in existence is measured as the time period (in years) since certification of the zone ${ }^{20}$ until $1990 . .^{21}$ Knowing the month of certification allows the duration to be expressed as a fraction of a year for zones certified in 1990. For example, the duration of zones certified in June 1990 is 0.5 years and for those certified in September 1990 is 0.3 years. There are a number of zones that are certified after 1990 and the duration variable for these zones takes a zero value. For the non-EZ block groups, the duration variable takes a zero value. (For zone areas, zero is used to represent a zone that is not in place in 1990. This is a valid representation of the non-EZ areas, too, since at that time they are not designated as zones.)

4) Duration squared is self-explanatory. It is calculated as duration*duration for every area.

18 I do not take into account CRAs certified after 1994 because I am looking at the overlap of CRA and EZ areas in 1990. Since data on the unemployment rate are available for Census block groups in 1990, I am interested in examining whether the unemployment rate is affected by the presence of a tax incentive program at that time.

19 It might have been clearer if I had included a separate dummy for a CRA and another for an EZ. I combine the CRA dummy with the EZ dummy because I know which (block group) areas contain only EZs (because the EZs are mapped into a GIS file), but I do not know which areas are only CRAs in terms of Census block groups (because the map of CRAs has not been prepared by the Ohio Department of Development). Based on my discussions with the $282 \mathrm{CRA}$ administrators in the state, I only know when the EZ and CRA areas coexist, when they overlap, and when they do not.

20 It should be noted that zones that are once certified can expire if the project the community is interested in requires zone designation only for a short period of time or for other reasons. The fact that some areas are EZs at the beginning of the EZ period in the state (post-1982) but are not at present could greatly complicate the analysis. For example, suppose an area is an EZ from 1982 to 1989, but is so successful that it is no longer an EZ. In such a case, a regression of the unemployment rate done on the status of the area being a current EZ would miss the true impact from 1982-89. That is, if the expired zones are included (as nonzone areas) in the data set and they expired before 1990, then the duration variable would show the wrong effect for them. However, it should be noted that if the number of decertifications is small there should be no problem. In my sample, only 8 of the 322 zones are decertified. I have excluded these zones from my sample. So, the exclusion of the expired zones should not pose a problem for the estimation.

21 I define the duration variable through 1990 because although my GIS map of Ohio's zones is current as of 1996, my Ohio Census block group map is current as of 1990. Remember that the unit of estimation is the Census block group. 
5) The area's manufacturing base is measured as the proportion of all employment in the block group that is employed in manufacturing jobs. ${ }^{22}$

6) The area's service base is the proportion of employment in the block group that is employed in service industry jobs. Note that, typically, the variables defined in (5) and (6) plus the percentage employed in other industries add up to 100 percent. 23

7) The area's occupational composition in professional specialty, technical, and administrative occupations is measured as the percentage of its employment in managerial and professional specialty occupations ${ }^{24}$ and technical, sales, and administrative support occupations. 25

8) The area's base in service occupations refers to the percentage of employment in private household occupations, protective service occupations, and other service occupations. Note that, again, the variables described in (7) and (8) plus the percentage employed in other occupations add up to 100 percent. ${ }^{26}$

9) A dummy is created at the Census tract level if population loss has occurred in a Census tract over the period 1980-90. If a Census tract in 1980 is further subdivided in 1990 (into a larger number of block groups-this is usually done if a tract grew over the period) or if its population has increased over 1980-90, the population loss dummy for the Census tract takes a zero value. Otherwise, it takes the value one, meaning that population loss has occurred in the tract. Net population change (at the county level) is computed as the change in population (in thousands) from 1980 to 1990: (1990 county population - 1980 county population) $/ 1,000$. If this variable is positive, the county gained population from 1980 to 1990, if negative, it lost population.

10) The poverty rate (multiplied by 100 for a percentage) is calculated as the ratio of the number of persons in the block group who had 1989 incomes below the poverty level to all persons in the block group.

11) The percentage of vacant housing units is calculated as the ratio of vacant housing units to all housing units (occupied and vacant) in the block group (again, multiplied by 100).

12) For the county unemployment rate, the unemployment rate of the county (in which the block group is located) at the time of zone designation (1982) is used.

13) Age is measured in years. I have excluded ages below 17 to ensure that no children are included in any computations or estimations.

14) The dummy for male $=1$ for male and 0 for female.

15) The proportion African American is calculated as the ratio of persons with African American origin to all persons in the block group.

16) The proportion with bachelor's degrees is the ratio of those with bachelor's degrees to all persons over 17 years old in the block group.

22 This variable is converted to a percentage by multiplying the calculated rate by 100 .

${ }^{23}$ It is not possible to include such a residual category variable in the estimation along with these two variables because then the three variables would add up to 100, creating a linear combination of variables in the system and hence collinearity.

${ }_{24}^{24}$ This category includes executive, administrative, and managerial and professional specialty occupations.

25This refers to technicians and related support, sales, and administrative support including clerical occupations.

26 See Footnote 23. The same explanation as for industries applies here. 
Table 1 shows the descriptive statistics for the variables used in the estimation. The descriptive statistics are for the 11,445 Census block groups (the entire state of Ohio consists of 11,621 Census block groups) used in the estimation. ${ }^{27}$ The mean for the tax incentive dummy shows that 78 percent of areas $(8,961$ out of the 11,445 block groups) in the state have a tax incentive program in place in 1990, leaving 22 percent (the remaining 2,484 block groups) as non-tax incentive areas.

TABLE 1

Descriptive Statistics for Variables

\begin{tabular}{lrccc}
\hline Variable & Mean & Std. Deviation & Minimum & Maximum \\
\hline Block group unemployment rate & 6.85 & 6.66 & 0 & 83.08 \\
Tax incentive program & 0.78 & 0.41 & 0 & 1 \\
Duration of program & 1.46 & 1.95 & 0 & 7 \\
Duration of program squared & 5.94 & 10.30 & 0 & 49 \\
\% African American & 12.55 & 26.42 & 0 & 100 \\
\% bachelor's degrees & 9.34 & 8.88 & 0 & 100 \\
\% male & 48.15 & 5.42 & 0 & 73 \\
Age (years) & 44.35 & 5.05 & 20 & 1 \\
Population loss & 0.53 & 0.50 & 0 & 92.31 \\
County population change & -22.14 & 69.57 & -207 & 100 \\
\% manufacturing employment & 23.37 & 11.14 & 0 & 100 \\
\% service employment & 31.47 & 11.97 & 0 & 100 \\
\% professional employment & 51.77 & 17.72 & 0 & 100 \\
\% service occupation & 14.79 & 9.31 & 0 & 100 \\
Poverty rate & 14.52 & 15.82 & 0 & 100 \\
\% vacant housing units & 6.50 & 7.40 & 0 &
\end{tabular}

There is much variation in the unemployment rate, with a high of 83.08 percent (Census block group in the city of Toledo EZ, Lucas County ${ }^{28}$ ). There are several Census block groups that have a 0 percent unemployment rate ${ }^{29}$ (these are supposedly the limited-authority zones or CRAs for which high unemployment is not required for offering tax incentives). On average, the tax incentive areas are in existence for a little longer than two years. Some zones/tax incentive areas are in existence for nearly seven years, probably having been designated when the tax incentive program came into existence in the state. The dummy for population loss indicates that, on average, nearly 53 percent of the state's Census tracts have experienced population loss over the period 1980-90. The data on net population change for the county in which the block group is located reinforces this, indicating that, on average, each county lost about 22,000 residents over the period.

On average, about 12 percent of the population in the block groups is African American. The average age of the population in the block groups is about 44 , with men and women about equally distributed. Finally, as one expects, the proportion with bachelor's degrees is less than 10 percent in all the block groups, on average.

27 Out of the 11,621 block groups, 176 block groups have missing data on at least one of the independent variables and so 11,445 census block groups are used in the estimation. It may be noted that estimation is performed only on those cases for which no data are missing in any of the independent variables.

28 The Toledo EZ has 367 block groups, one of which has an unemployment rate of 83.08 percent ( 37 unemployed persons out of a labor force of 43).

29One of these is in a Census block group in the village of Bluffton EZ, Allen County (no unemployed persons out of a labor force of 338). 
In terms of the areas' economic bases, on average, the service base accounts for 31 percent of total employment while the manufacturing base accounts for only 23 percent of total employment. In terms of occupational composition, a majority (52 percent) of employment is in professional specialty, technical, and administrative occupations while service occupations, such as household services, account for only about 15 percent of employment. On average, about 15 percent of the population in the block groups have 1989 incomes below the poverty level. Finally, the data for vacant housing units indicate that, on average, about 7 percent of housing units are vacant at the time of the Census survey. This implies that a majority of areas would qualify for zone designation. It may be recalled that a prevalence of vacant industrial/commercial facilities, a minimum of 5 percent, is required for zone designation.

\section{RESULTS FROM ESTIMATION}

Table 2 shows the results from the OLS and 2SLS estimations of unemployment rate. ${ }^{30}$ The OLS estimation considers the tax incentive dummy as exogenous and is a simple regression of the unemployment rate. The 2SLS estimation considers tax incentives as endogenous and uses factors that determine zone designation (tax incentives) as instruments for the endogenous tax incentive dummy.

TABLE 2

Estimation of Unemployment Rate

\begin{tabular}{|c|c|c|c|c|}
\hline \multirow{2}{*}{$\begin{array}{l}\text { Variable } \\
\text { Constant }\end{array}$} & \multicolumn{2}{|c|}{ OLS Estimates (SE) } & \multicolumn{2}{|c|}{ 2SLS Estimates (SE) } \\
\hline & 12.266 & $(1.678)^{*+44}$ & 16.245 & $(1.984)^{* * *}$ \\
\hline Tax incentive program & 0.0303 & $(0.1127)$ & -4.5263 & $(0.9469)^{* * *}$ \\
\hline Duration of program & 0.4595 & $(0.1157)^{* * *}$ & 1.8177 & $(0.3031)^{* * * *}$ \\
\hline Duration squared & -0.0256 & $(0.0231)$ & -0.2173 & $(0.0458)^{* * *}$ \\
\hline$\%$ manufacturing employment & 0.0323 & $(0.0112)^{* * * *}$ & 0.0342 & $(0.0113)^{* * *}$ \\
\hline$\%$ service employment & 0.0332 & $(0.0113)^{* * *}$ & 0.0260 & $(0.0116)$ \\
\hline$\%$ professional employment & -0.0895 & $(0.0105)^{* * *}$ & -0.0901 & $(0.0106)^{* 4 *}$ \\
\hline$\%$ service occupation & 0.0638 & $(0.0184)^{* * *}$ & 0.0626 & $(0.0186)^{* * *}$ \\
\hline$\%$ African American & 0.0649 & $(0.0039)^{* * *}$ & 0.0616 & $(0.0040)^{* * *}$ \\
\hline Mean age & -0.0585 & $(0.0162)^{* * *}$ & -0.0816 & $(0.0177)^{* * * *}$ \\
\hline$\%$ male & -0.0334 & $(0.0201)^{*}$ & -0.0296 & $(0.0204)$ \\
\hline$\%$ bachelor's degrees & -0.0745 & $(0.0135)^{* * *}$ & -0.0904 & $(0.0142)^{* * *}$ \\
\hline $\mathrm{N}$ & \multicolumn{2}{|c|}{11,445} & \multicolumn{2}{|c|}{11,445} \\
\hline $\mathbf{R}^{2}$ & \multicolumn{2}{|c|}{0.32} & \multicolumn{2}{|c|}{0.26} \\
\hline
\end{tabular}

***Statistically significant at the $1 \%$ level.

*Statistically significant at the $10 \%$ level.

aSE refers to the standard error of the estimate.

The impact on the unemployment rate of tax incentives shown in the regressions is plausible if the assumptions of the estimation methods are taken into account. ${ }^{31}$ The OLS specification shows that tax incentives do not have a statistically significant impact on the unemployment rate of areas. When combined with the statistically significant duration variable and its square, the coefficient on

30The equations are all estimated using the econometric software LIMDEP.

31 OLS estimates are presented along with the 2SLS estimation results because the OLS estimates interestingly show the endogeneity of the tax incentive dummy. 
tax incentives in the OLS estimation may be interpreted as follows. An area with a tax incentive program sees an increase in its unemployment rate by about 0.46 percentage points in a year: 0.0303 (coefficient on the tax incentive dummy in the OLS estimation) +0.4595 (coefficient on the duration variable in the OLS estimation) $* 1$ year -0.0256 (coefficient on the duration squared variable in the OLS estimation) $* 1^{2}$. Areas that have tax incentive programs for two years see an increase in their unemployment rate by about 0.84 points: $0.0303+0.4595 * 2$ years -0.0256 $* 2^{2}$, and so forth. Thus, with the OLS estimation, it appears as if tax incentive programs actually increase the unemployment rate of areas. In reality, the tax incentive program is such that the causality runs in the opposite direction: areas are designated as EZs or tax incentive areas because they have a high unemployment rate (or meet one of five other criteria).

When the endogeneity of tax incentives is taken into account (in the 2SLS specification), its coefficient has a negative sign and is statistically significant. This indicates that tax incentive programs reduce the unemployment rate of areas, consistent with our expectations. Further, when I consider the impact of the tax incentive along with the duration of its existence, I can say something about its net impact. The net impact of being a tax incentive area versus not being one for periods of one, two, three, four, five, six, and seven years is:32 -2.92 (i.e., $-4.5263+$ $1.8177 * 1-0.2173 * 1^{2}$ ), -1.76 (i.e., $-4.5263+1.8177 * 2-0.2173 * 2^{2}$ ), $-1.03,-0.73$, $0.87,-1.44$, and -2.45 percentage points, respectively. ${ }^{33}$ Thus, if an EZ (or other tax incentive area) had 10 unemployed persons out of a laber force of 100 persons in 1982 (when it is designated, with an unemployment rate of 10 percent), the model predicts that the area's unemployment in 1983 would be 7.08 percent $(2.92$ percentage points less). Taking into account the fact that a 3 percentage point reduction over a period of one year translates to about three persons obtaining gainful employment with the EZ or other tax abatement program in place, these results are plausible.

One could doubt the plausibility of the estimate, which shows that the unemployment rate moves 2.9 percentage points in the first year, given that the mean unemployment rate is 6.85 percent. It should be remembered that the estimation of unemployment rate is done at the Census block group level. The variation in the unemployment rate across the 11,445 Census block groups is quite large, with a minimum of 0 percent and a maximum of 83.08 percent (Table 1). With this large variation, it is easy to see the 2.9 percentage point reduction. Consider the example of a firm that creates 100 jobs in the first year of its existence in the zone. Assume that 97 out of these 100 new jobs are allocated to labor force that might migrate into the area with increased job growth, consistent with what the

${ }^{32}$ The impact of the $\mathrm{EZ}$ is calculated as the coefficient on the tax incentive dummy plus the impact of the duration of the tax incentive (the sum of coefficients on the duration variable and its square) when it has been in existence for a year. Impacts for other years are calculated in a similar manner.

${ }^{33}$ In order to check whether the quadratic in duration is properly specified, I categorize the residual from this regression and compute means for four groups according to values of duration (duration $\leq$ one year, duration between one and three years, three and five years, and five and seven years, seven years being the sample maximum for duration). When I do this, the following are the means of the residuals for the various groups: $0.08,-0.26$ -0.17 , and 0.70 , respectively. Thus, the residual means vary randomly across the various groups and there appears to be no monotonicity. This shows that the duration equation is properly specified. 
migration literature (see Bartik 1991 for a summary of this literature) has argued. The remaining three jobs are held by zone residents. Assuming that these three are among the original ten unemployed in the zone, the unemployment of the area falls by 3 percentage points (from 10 percent to 7 percent) in the first year. As another qualification to this result, it should be remembered that the tax incentive dummy in the regression is used as a measure of a tax abatement program in place-either EZ or CRA program tax incentives for job creation. With this in mind, from the data, I think that the effectiveness of the EZ program or tax incentives in general is indeed apparent enough to register.

These results, while plausible, appear to be smaller in impact than what Papke (1994) reported in her evaluation of Indiana's EZ program. Papke (1994) reports a 19 percent reduction in unemployment claims in Indiana due to the existence of the EZ program. The difference in the magnitude of the impact between this and Papke's (1994) study could be due to the way in which the presence of the tax incentive program and the unemployment rate are measured in these studies. Papke's (1994) variable measures the impact of just the EZ. Here, the dummy for tax incentive programs takes into account the other tax incentive program (CRA) in Ohio, in addition to the EZ. If the CRA program is not accounted for, a decrease (or increase) in the unemployment rate might have been noted that is not attributable to the tax incentive. Therefore, in the context of Ohio, use of the general dummy for tax incentive programs is more appropriate than the single measure of the EZ that Papke (1994) uses. Papke (1994) also uses data on unemployment claims in Indiana whereas I use the actual unemployment rate. The superiority of self-reported data on employment when compared to that on unemployment claims is clear (see the section on data). From this perspective, the impact of tax incentive programs obtained here is much more plausible than the 19 percent reduction in unemployment claims Papke (1994) reports as being just due to the EZ. While the reason for the difference in the magnitude of the coefficients between Papke's (1994) study and this study seem obvious, the results are consistent and show that EZ and CRA programs reduce the unemployment rate of the areas adopting them.

The other variables in the estimation have mostly the expected effects on the unemployment rate. The manufacturing base and the proportion of employment in service occupations positively affect an area's unemployment rate, consistent with expectations. The percentage of employment in technical and administrative occupations has a negative impact on unemployment, indicating that the higher the percentage employed in such routine occupations, the lower the unemployment rate of the area. This is what one would expect since these are occupations for which demand would not decline even during periods of high unemployment. The percentage of an area's employment in the service industry has a positive impact in the OLS specification, contrary to expectation, but loses its significance in the 2SLS version. 
The demographic structure of an area also influences its unemployment rate. Higher proportions of African Americans increase the unemployment rate and the effect is statistically significant in the regressions, as expected. This is because African Americans in general tend to have poorer job skills, thus leading to higher unemployment. Younger areas (where the mean age is lower) and those with a lower proportion of men have higher unemployment rates, as expected. Younger persons are likely to have less work experience and hence look for jobs longer, thus increasing the area's unemployment rate. Men are more likely to be employed because of better matching of skills and opportunities, and also because they tend to be the primary household income earners. The percentage with bachelor's degrees has the expected sign, indicating that the higher the proportion of college graduates, the lower is the unemployment rate of the area (by about 0.10 percentage points in the 2SLS specification). Thus, better-educated areas have lower unemployment rates, which is to be expected.

The R-squared for the model indicates that 26 percent of the variation in the unemployment rate is explained by variables in the model. Although this is low, it should be remembered that the R-squared is only a descriptive statistic. In cross-sectional data, a lower R-squared might occur, even if the model is a satisfactory one, because of the large variation across individual units of observation (see Pindyck and Rubinfeld 1991). This suggests that the R-squared alone may not be a suitable measure of the explanatory power of a model.

Table 3 replicates the 2SLS specification in Table 2 with the duration variables as dummies rather than as continuous variables. The same variables as in Table 2 are used as instruments for the endogenous tax incentive dummy.

\section{TABLE 3}

Estimation of Unemployment Rate with Dummies for Duration

\begin{tabular}{lrl}
\hline Variable & \multicolumn{2}{c}{ 2SLS Estimates (SE) } \\
\hline Constant & 18.949 & $(1.669)^{* * *}$ \\
Tax incentive program & -6.9831 & $(0.8635)^{* * *}$ \\
\% manufacturing employment & 0.0314 & $(0.0086)^{* * *}$ \\
\% service employment & 0.0289 & $(0.0091)^{* * *}$ \\
\% professional employment & -0.0850 & $(0.0080)^{* * *}$ \\
\% service occupation & 0.0392 & $(0.0142)^{* * *}$ \\
\% African American & 0.0534 & $(0.0033)^{* * *}$ \\
Mean age & -0.1087 & $(0.0149)^{* * *}$ \\
\% male & -0.0335 & $(0.0166)^{* *}$ \\
\% bachelor's degrees & -0.1037 & $(0.0117)^{* * *}$ \\
Duration of program: 0-1 year & 3.5911 & $(0.4059)^{* * *}$ \\
Duration of program: 1-3 years & 3.8050 & $(0.4024)^{* * *}$ \\
Duration of program: 3-5 years & 4.6721 & $(0.4240)^{* * *}$ \\
Duration of program: 5-7 years & 4.7664 & $(0.5926)^{* * *}$ \\
& \multicolumn{3}{|c}{11,445} \\
N & 0.16 \\
R & \multicolumn{3}{|c}{} \\
\hline
\end{tabular}

***Statistically significant at the $1 \%$ level.

**Statistically significant at the $5 \%$ level. 
The signs on the independent variables remain as in the previous estimation. Once again, the proportion of employment in the service industry has a positive impact on the unemployment rate, contrary to expectations, indicating that the higher the proportion of jobs in the service industry, the higher is the unemployment rate of the area. This effect is probably due to the fact that there are areas in the sample that have no employment in service industry, but also have a low unemployment rate. This also explains why this variable has a positive impact in the OLS specification in Table 2.

Table 3 shows that tax incentives continue to have the expected negative sign, which is statistically significant at the $1 \%$ level. When combined with the effect of the signs on the duration dummies, the impact for areas that have been tax incentive areas for one year is a decrease in the unemployment rate by 3.39 percentage points $(-6.9831+3.5911 * 1)$. The impact for an area that has been providing tax incentives between one and three years is an increase in the unemployment rate by 0.63 percentage points $(-6.9831+3.8050 * 2)$. The impacts for areas having tax incentives from three to five years and five to seven years are increases in their unemployment rates by 12 percentage points $(-6.9831+4.6721 * 4)$ and 22 percentage points $(-6.9831+4.7664 * 6)$, respectively. ${ }^{34}$ Thus, it is a robust finding across the regressions that, at least initially, tax incentives have a statistically significant impact in reducing the unemployment of areas that adopt them, consistent with the objective for which the program was initiated in Ohio in 1982.

\section{POLICY IMPLICATIONS AND CONCLUSION}

While the regressions support the notion that areas with tax incentives see a reduction in their unemployment, there is lesser consensus regarding the duration for which the tax incentives should be offered. The regression in which duration is included as dummies suggests that three to five years could be the optimum period for maximizing the effect of tax incentives on unemployment rate, after which it is preferable for the area to cease offering incentives. In terms of policy action, this translates into decertifying areas that have been tax incentive areas for longer than five years. If incentives continue for periods longer than three to five years, it is likely that their unemployment problems will return. The reason for this is that, over time, tax incentives could degenerate into employment redistribution games that have the effect of increasing the unemployment of areas that lose firms.

However, this research does not shed any light on the zero-sum nature of EZs. I have not done any analysis, real or hypothetical (as in Sridhar 1996), to show the effects of redistributing employment from one area to another and what the effects are likely to be. This paper also does not answer the question as to whether the high cost of generating a few jobs with generous tax abatements is worth the modest gains in reducing unemployment. I deal with this issue in

${ }^{34}$ It may be noted that the effect of the EZ on the unemployment rate is calculated in a very similar manner as in the previous estimation. It is calculated as the sum of the coefficient on the tax incentive dummy and the coefficient on duration multiplied by the period for which one is interested in knowing the impact. 
Sridhar (1998). It must be acknowledged that tax incentives, being place-oriented policies, are only one way of increasing employment. There might be other, more efficient ways of reducing area unemployment, such as relocation and training programs, that are people oriented.

In any case, increasing employment has the effect of increasing households' labor force participation rates (measured as the ratio of employment to population). This has hysteresis effects on the labor market, as Bartik (1991) has argued. Hysteresis is a term borrowed from physics to explain how the electromagnetic properties of certain metals are permanently affected by the temporary application of certain magnetic forces. When applied to the labor market, this means that the increase in the labor force participation rate due to increased employment increases households'. employability (due to training and acquisition of skills) in the long run. From this perspective, tax incentive programs in Ohio most probably created these hysteresis effects in the labor market through increasing productivity, employment, and labor force participation.

\section{REFERENCES}

Ashenfelter, Orley. "Estimating the Effect of Training Programs on Earnings." Review of Economics and Statistics (1977), 47-57.

Barron, J., and W. Mellow. "Changes in the Labor Force Status among the Unemployed." Journal of Human Resources 16 (1981), 427-441.

Bartik, Timothy J. Economic Development Strategies. Kalamazoo, MI: W.E. Upjohn Institute for Employment Research, 1995.

. Who Benefits From State and Local Economic Development Policies? Kalamazoo, MI: W.E. Upjohn Institute for Employment Research, 1991.

Boarnet, Marlon, and William T. Bogart. "Enterprise Zones and Employment: Evidence from New Jersey." Journal of Urban Economics 40 (2) (1996), 198-215.

Butler, Stuart M. Enterprise Zones: Greenlining the Inner Cities. New York: Universe Books, 1981.

Byrnes, Patricia, and Kala Sridhar. "City-Firm Bargaining Decisions in Ohio's Urban Enterprise Zones." Paper presented at the Association for Public Policy and Management Research Conference, Pittsburgh, PA, 1996.

Coopers and Lybrand. "Lake County Enterprise Zone Study." Report for Lake County (Ohio) Economic Development Center, Lake County (Ohio) Board of Commissioners, Ohio Department of Development, City of Eastlake, Ohio, and City of Wickliffe, Ohio, 1993.

Courant, Paul N. "How Would You Know a Good Economic Development Policy if You Tripped Over One? Hint: Don't Just Count Jobs." National Tax Journal 47 (1994), 863-881.

Dabney, Dan. "Do Enterprise Zone Incentives Affect Business Location Decisions." Economic Development Quarterly 5 (4) (1991), 325-334.

Ehrenberg, Ronald G., and Robert S. Smith. Modern Labor Economics. Glenview, IL: Scott, Foresman and Co., 1994. 
Eisinger, Peter. "State Economic Development in the 1990s: Politics and Policy Learning." Economic Development Quarterly 9 (2) (1995), 146-158.

Erickson, Rodney A., and Susan Friedman. Enterprise Zones: An Evaluation of State Government Policies. Report Prepared for the U.S. Department of Commerce, Economic Development Administration, Washington, D.C., 1989.

Feldstein, Martin. "The Private and Social Costs of Unemployment." American Economic Review 68 (2) (1978), 155-158.

Ge, Wei. "The Urban Enterprise Zone." Journal of Regional Science 35 (2) (1995), $217-231$. Ham J.C., and R.J. LaLonde. "The Effect of Sample Selection and Initial Conditions in Duration Models: Evidence from Experimental Data on Training." Econometrica 64 (1) (1996), 175-205.

Hill, Edward. "Tax Abatement War Within the State." Draft manuscript, Levin College of Urban Affairs, Cleveland State University, 1994.

Holzer, Harry J. "Reservation Wages and their Labor Market Effects for Black and White Male Youth." Journal of Human Resources 21 (1986), 157-177.

Korenman, S., and D. Neumark. "Does Marriage Really Make Men More Productive." Journal of Human Resources 26 (1991), 282-307.

LeRoy, Greg. "No More Candy Store: How States and Cities Can End Civil Wars Over Jobs." State Tax Notes 4 (1994), 510-513.

Levitan, S., and E. Miller. "Enterprise Zones Are No Solution for Our Blighted Areas." Challenge 35 (3) (1992), 4-8.

Marvel, Mary, and William Shkurti. "The Economic Impact of Development: Honda in Ohio." Economic Development Quarterly 7 (1993), 50-62.

Netzer, Dick. "An Evaluation of Interjurisdictional Competition Through Economic Development Incentives." In Daphne A. Kenyon and John Kincaid (eds.) Competition among States and Local Governments: Efficiency and Equity in American Federalism. Washington, D.C.: The Urban Institute Press, 1991.

Pantuosco, Lou, and Darrell Parker. "Sources of Prevailing Differences in Unemployment Rates for Selected Regional Pairs." The Review of Regional Studies 28 (2) (1998), 35-46.

Papke, Leslie. "Tax Policy and Urban Development: Evidence from the Indiana Enterprise Zone Program." Journal of Public Economics 54 (1994), 37-49.

Pindyck, Robert S., and Daniel L. Rubinfeld. Econometric Models and Economic Forecasts. New York: McGraw-Hill Inc., 1991.

Rubin, Barry, and Margaret Wilder. "Urban Enterprise Zones: Employment Impacts and Fiscal Incentives." Journal of the American Planning Association 55 (1989), 418-431.

Rubin, Barry, and Kurt Zorn. "Sensible State and Local Economic Development." Public Administration Review 45 (1985), 333-339.

Rubin, Marilyn, and Regina Armstrong. The New Jersey Urban Enterprise Zone Program: An Evaluation. Wayne, NJ: Urbanomics, 1989. 
Schwartz, Aba. "Interpreting the Effect of Distance on Migration." Journal of Political Economy 81 (1973), 1153-1167.

Seyfried, William. "The Impact of Enterprise Zones on Local Economies." Ph.D. diss., Purdue University, 1990.

Sridhar, Kala S. "Tax Costs and Employment Benefits of Enterprise Zones." Economic Development Quarterly 10 (1996), 69-90.

"Urban Economic Development in America: Evidence from Enterprise Zones." Ph.D. diss., The Ohio State University, 1998.

Staley, Sam. Can Enterprise Zones Revitalize the Central City? An Ohio Case Study. Regional Policy Report 1. Dayton, OH: Urban Policy Research Institute, 1991.

Theirl, S. "AStrategy for Community Investment: The Western Reserve Enterprise Zone, Summit County, Ohio." Master's thesis, University of Akron, 1994.

Tobin, James. "Inflation and Unemployment." American Economic Review 62 (1972), $1-18$.

U.S. Department of Housing and Urban Development. Office of Program Analysis and Evaluation. State Designated Enterprise Zones: Ten Case Studies. Washington, D.C., 1986.

U.S. General Accounting Office. Enterprise Zones: Lessons from the Maryland Experience. Washington, D.C., 1988.

Wilder, Margaret. "Rhetoric versus Reality." Journal of the American Planning Association 26 (4) (1996), 473-491. 